\title{
Successful endovascular repair of symptomatic aberrant left subclavian artery arising from Kommerell diverticulum with the chimney technique
}

Zhong Hai, $\mathrm{PhD},{ }^{\mathrm{a}}$ Wang Maohua, $\mathrm{PhD},{ }^{\mathrm{b}}$ and Shao Guangrui, $\mathrm{PhD}^{\mathrm{a}}$

\footnotetext{
From the ${ }^{\mathrm{a}}$ Department of Radiology, the Second Hospital of Shandong University; and ${ }^{\mathrm{b}}$ Department of Vascular Surgery, Shandong Provincial Hospital, Jinan, Shandong, China.

This work was supported by the Seed Fund of the Second hospital of Shandong University (S2013010020). Disclosures: Authors have nothing to disclose with regard to commercial support.

Received for publication July 10, 2016; revisions received Sept 13, 2016; accepted for publication Sept 26, 2016; available ahead of print Nov $9,2016$.

Address for reprints: Shao Guangrui, PhD, Department of Radiology, Second Hospital of Shandong University, 247\# Beiyuan Rd, Jinan, Shandong 250033, China (E-mail: shaoguangrui@163.com).

J Thorac Cardiovasc Surg 2017;153:806-8

$0022-5223 / \$ 36.00$

Copyright $\odot 2016$ by The American Association for Thoracic Surgery

http://dx.doi.org/10.1016/j.jtcvs.2016.09.070
}

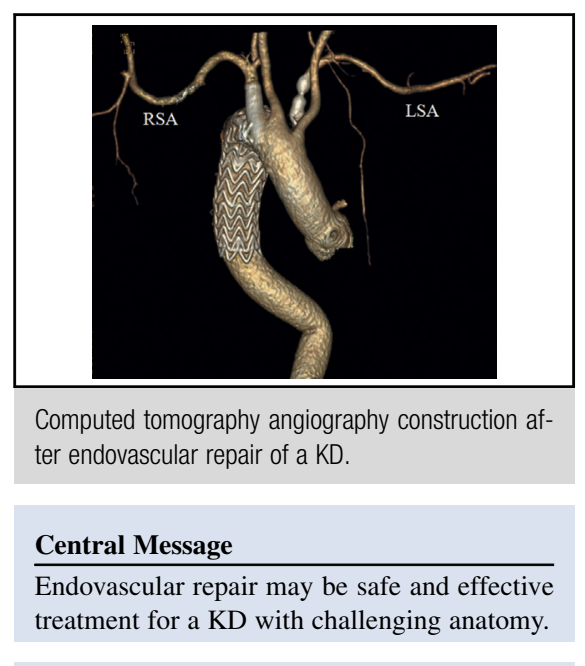

See Editorial Commentary page 809.
A 57-year-old dysthymic woman presented with dysphagia for 2 months. Axial computed tomography angiography (Figure 1) demonstrates a right-sided aortic arch and a 5.3-cm Kommerell diverticulum (KD). The esophagus (Figure 1, dotted ring) is compressed by a large KD. Computed tomography reconstruction of volume rendering (Figure 2) reveals an aberrant left

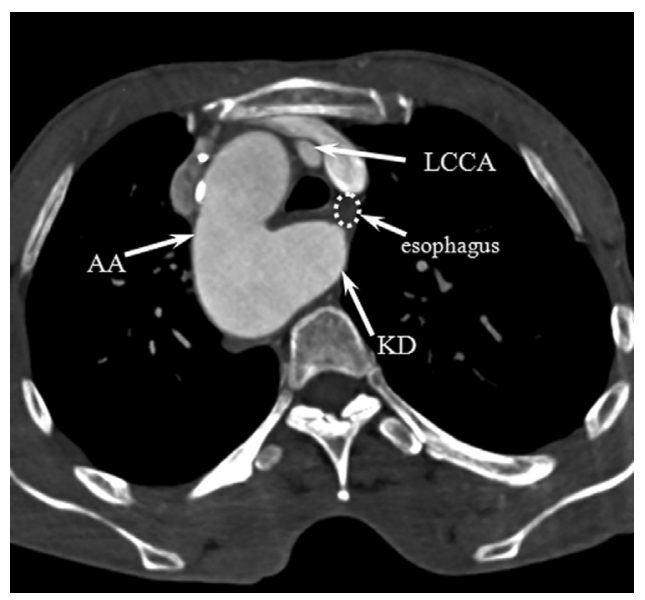

FIGURE 1. Axial computed tomography angiography image of KD with right aortic arch. $A A$, Aortic arch; $K D$, Kommerell diverticulum; $L C C A$, left common carotid artery. subclavian artery arising from the KD. Volume rendering (Figure 2) shows the right-sided aortic arch branches to be as follows: left common carotid artery, right common artery, right subclavian artery, and left subclavian artery.

Aortogram (Figure 3, 1) shows right-sided aortic arch with aberrant left subclavian artery originating from

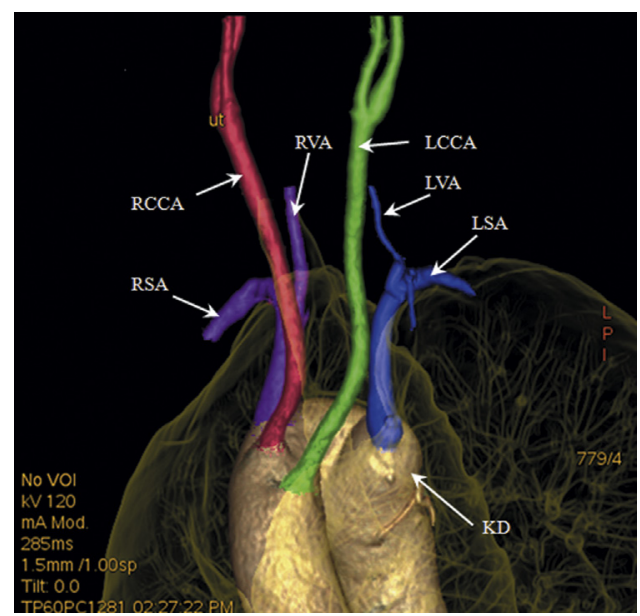

FIGURE 2. Volume-rendering image of aberrant left subclavian artery and KD. RCCA, Right common carotid artery; RSA, right subclavian artery; $R V A$, right vertebral artery; $L C C A$, left common carotid artery; $L V A$, left vertebral artery; $L S A$, left subclavian artery; $K D$, Kommerell diverticulum. 


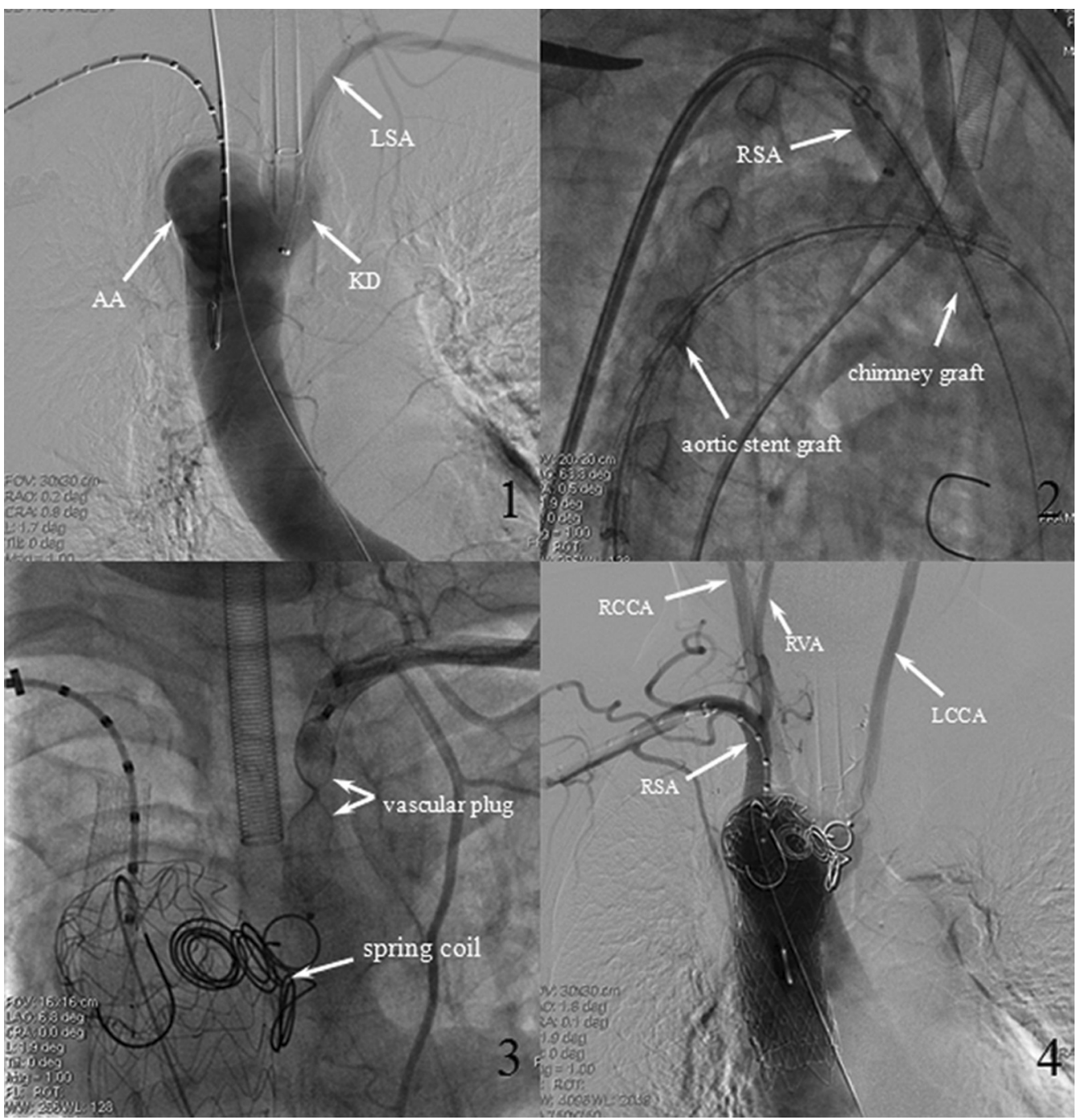

FIGURE 3. Endovascular repair of KD with right aortic arch. $A A$, Aortic arch; $K D$, Kommerell diverticulum; LSA, left subclavian artery; RSA, right subclavian artery; $R C C A$, right common carotid artery; $R V A$, right vertebral artery; $L C C A$, left common carotid artery.

the KD. Angiography confirms the presence of a dominant right vertebral artery. A stent (GORE VIABAHN [WL Gore \& Associates, Inc, Flagstaff, Ariz], $10 \times 50 \mathrm{~mm})$ is implanted retrograde into the right subclavian artery, and the chimney stent is positioned (Figure 3,2). The thoracic aortic stent graft (GORE TAG [WL Gore \& Associates, Inc], $34 \times 150 \mathrm{~mm}$ ) is deployed, and the chimney stent is quickly deployed (Figure 3, 2). Three spring coils (Cook Medical Inc, Bloomington, Ind) and a $14-\mathrm{mm}$ vascular plug II (AGA Medical Corp, Plymouth, Minn) are locked in the origin and the proximal part of the left subclavian artery, respectively (Figure 3,3). The aberrant left subclavian artery is occluded, and the left vertebral artery is unblocked. There is no retrograde left subclavian artery endoleak. Angiography demonstrates successful exclusion of the $\mathrm{KD}$ and patency of the right subclavian artery using the

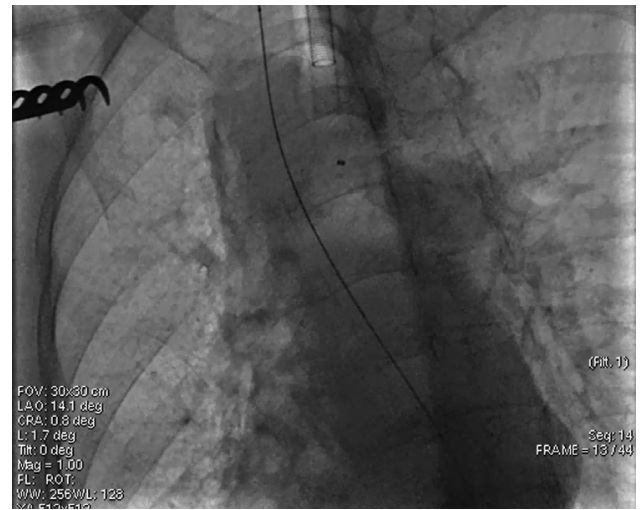

VIDEO 1. Endovascular repair with the chimney technique of $\mathrm{KD}$. Video available at: http://www.jtcvsonline.org/article/S0022-5223(16) 31394-0/addons. 


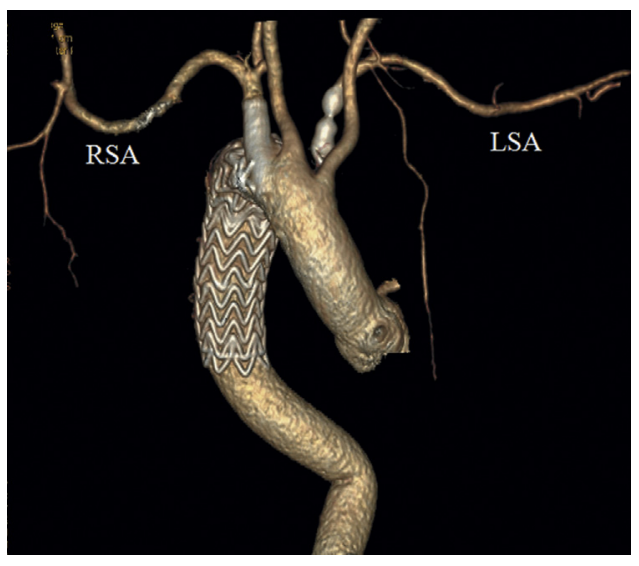

FIGURE 4. Computed tomography angiography construction after endovascular repair of KD. RSA, Right subclavian artery; $L S A$, left subclavian artery.

endograft with the chimney technique (Figure 3, 4). Retrograde blood flow in the left vertebral artery was shown after left subclavian artery occlusion (Video 1). Computed tomography angiography confirmed the patency of the right subclavian artery (Figure 4). The patient's postoperative recovery was uneventful, and she was discharged on postoperative day 8 . The patient remained well without ischemia, and her symptoms of dysphagia progressively improved.

Right-sided aortic arch with $\mathrm{KD}$ and aberrant left subclavian artery is a rare pathology. ${ }^{1,2}$ Endovascular repair with the chimney technique was feasible in this case, avoiding the complex open surgery procedure. ${ }^{3}$

\section{References}

1. Hsu HL, Huang CY, Chen JS. Total endovascular repair for acute type B dissection in the setting of right aortic arch with aberrant left subclavian artery and Kommerell diverticulum. J Thorac Cardiovasc Surg. 2015;150:409-11.

2. Shaikh FM, Hurley A, Buckley O, Tierney S. Kommerell's diverticulum, a right-sided aortic arch, and a hypoplastic left vertebral artery arising from the left common carotid artery. J Vasc Surg. 2014;60:1059.

3. Monaco M, Lillo S, La Marca Giordano A, Contaldo A, Schiavone V. Endovascular repair of a right-sided thoracic aortic aneurysm with Kommerell diverticulum and aberrant left subclavian artery. Ann Vasc Surg. 2014;28: 1323.e1-5. 